\title{
HIP JOINT RANGE OF MOTION IN DIFFERENT CURVE TYPES OF CONSERVATIVELY MANAGED ADOLESCENTS WITH IDIOPATHIC STRUCTURAL SCOLIOSIS IN SRI LANKA
}

\author{
Ashan Wijekoon \\ Department of Allied Health Sciences \\ Faculty of Medicine \\ University of Colombo \\ Sri Lanka
}

\author{
Asha Wettasinghe \\ Department of Allied Health Sciences \\ Faculty of Medicine \\ University of Colombo \\ Sri Lanka
}

\author{
Chandu de Silva \\ Department of Pathology \\ Faculty of Medicine \\ University of Colombo \\ Sri Lanka
}

\begin{abstract}
Background: Adolescent idiopathic scoliosis (AIS) affects range of motion (ROM) of hip joint and normal gait parameters. These patients vary according to their curve types. Whether the hip ROM values differ between different curve types, and what their consequences would be in AIS, is not clear. Hence, the objective of this study was to investigate hip joint ROM values in different types of AIS curves. Materials and Methods: This cross-sectional analytical study included 75 AIS patients who presented to a scoliosis clinic and rheumatology clinics of two tertiary care hospitals. AP radiographs of the spine were reviewed, and the curves were classified according to Lenke. Hip ROM in all the three planes were measured using a universal goniometer and compared between different curve types and to normal population values. One-way ANOVA and independent-t-test were used to analyze data at 0.05 significance level, using SPSS version 22.0. Results: Mean Cobb value of the major curve of AIS patients was $34.64 \pm 14.05$. Majority $(65.3 \%)$ had single structural curves. Majority of the major curves had the convexity to the right side $(61.33 \%)$ and was located in the thoracic area $(69.3 \%)$. Commonest curve type was Lenke type 1 (44\%), with Lenke type 6 being the least common (9.3\%). None of the patients had Lenke type 4 curves. Effect of curve type was significant only on flexion ROM $(p<0.05)$, with a significant reduction in curve type 3 than the other curve types. Frontal and sagittal plane hip ROMs were significantly reduced in AIS patients compared to normal subjects $(\mathbf{p}<0.05)$. Conclusion: Reduction in flexion ROM probably contributes to the previously reported reduction in step length in AIS. In view of our findings, hip flexion ROM exercises should be considered in conservative management of AIS patients, especially those with Lenke type 3 curves.
\end{abstract}

Keywords - Adolescent idiopathic scoliosis; Hip joint range of motion; Lenke classification

\section{INTRODUCTION}

Scoliosis is defined as a spinal deformity characterized by lateral and rotational curvature by the Scoliosis Research Society [1]. It affects infants, adolescents and adults worldwide and about 2-3\% of adolescent population gets affected [2]. When seen in children aged 10-18 years and the exact cause is not known, the condition is called Adolescent Idiopathic Scoliosis (AIS). Among different scoliosis types AIS is considered as the most common type accounting for more than $75 \%$ of scoliosis. AIS has a female predominance with a $8: 1$ female to male ratio $[2,3]$.

Type of the spinal curve varies among AIS patients. The curve type depends on number of curves and the anatomical location of the curves, whether it is thoracic, thoracolumbar or lumber. In 2001, Lenke et al [4] introduced a new system for classifying AIS curve types that incorporated sagittal parameters in addition to coronal and flexibility measurements thus addressing limitations of the previous classification methods.

According to Lenke classification, thoracic curves are defined as curves with apices from $\mathrm{T} 2$ to $\mathrm{T} 11 / \mathrm{T} 12$, thoracolumbar curves as curves with apices from $\mathrm{T} 12$ to L1, and lumbar curves as curves with apices from L1/L2 to L4/L5 [4]. Primarily there are 6 sub types in this classification namely Main Thoracic (MT), Double Thoracic (DT), Double Major (DM), Triple Major (TM), Thoracolumbar/Lumbar (TL/L), Thoracolumbar/Lumbar - Main Thoracic (TL/L - MT) [4]. Generally, Lenke 1 curves correspond to MT curves and Lenke 5 curves correspond to TL curves. Among these six curve types, type 1 is the most prevalent type according to previous literature $[5,6]$.

AIS causes deformities of the spine in frontal, sagittal and transverse planes. As a result, numerous anatomical deviations 


\section{International Journal of Engineering Applied Sciences and Technology, 2020 \\ Vol. 5, Issue 5, ISSN No. 2455-2143, Pages 8-13 \\ Published Online September 2020 in IJEAST (http://www.ijeast.com)}

occur in AIS patients such as visible rib humps, shoulder height inequality, uneven hips, and leg length discrepancies [7]. Past studies on AIS patients, focused on pelvic asymmetries and gait parameters. These studies showed that the pelvis gets structurally changed in different aspects as a secondary complication of scoliosis [8-11] and that it affects the locomotor mechanism or the normal gait pattern of the patient [12]. Mahaudens et al (2009) [11] who studied gait parameters of AIS patients, found a significant reduction in step length and frontal plane hip movements in AIS patients compared to normal individuals. However, they did not focus on any association of these impairments with the curve type. Finding of a correlation between these parameters will help to decide and implement treatment plans for the management of these impairments. It will also individualize the treatment programmes according to the patient's curve type.

Since there is a close anatomical and biomechanical relationship between the pelvis and the hip joint, structural deformities of the pelvis in AIS patients might influence range of motion of hip movements. This may contribute to the changes in gait parameters. Previous studies have not focused on the range of motion of hip movements of AIS patients. They have been limited to a few movements of the hip joint, focusing mainly on transverse plane movements, neglecting the frontal plane and sagittal plane hip movements. Another limitation of previous studies has been inclusion of only the surgically operated AIS patients as the study sample. To fill this current gap in literature, this study was conducted to find a correlation between curve types and hip joint ROM values of conservatively managed AIS patients.

\section{MATERIALS AND METHODS}

This hospital based cross-sectional study was conducted in two tertiary care hospitals in Sri Lanka. We included 75 adolescents (69 females \& 6 males) with idiopathic structural scoliosis who were managed conservatively (brace wearing and/or physiotherapy) and whose postero-anterior (PA) radiographs of the whole spine were available and clearly visible. Control group comprised of 75 normal healthy individuals whose age and sex matched with the study group.

Data which were necessary for the Lenke curve type classification were collected by the principal investigator (AW) using the most recently taken PA radiographs including Cobbs angle measurement of the major curve. Then the curves were classified as Type 1 to 6 as described by Lenke (Table 1).

Universal goniometer, a plastic long, double armed device with scale marked 1800 in one-degree increments was used to measure the hip joint ROM in all the 3 planes (Sagittal Flexion and Extension, Frontal - Abduction and Adduction, Transverse - Internal Rotation and External Rotation) using the standard guidelines for the position of the patient/participant, therapist position, goniometric placement, starting and ending positions of the movement. All the measurements were taken by the principal investigator (AW).
Goniometric measurements are used by physiotherapists to quantify baseline limitations of motion, decide on appropriate therapeutic interventions, and document the effectiveness of these interventions [12].

We used the mean values of the sum of right and left ROM of each hip movement to get a collective idea about the hip joint ROM. These values were compared in six Lenke curve types and that of the control group values.

\section{Statistical analysis}

Data were expressed as frequencies and percentages, and means and standard deviations, when appropriate using descriptive statistics. One-way analysis of variance (ANOVA) was performed to compare mean values of ROM of hip joint movements among different curve types. When the overall effect was significant, Tukey post hoc tests was conducted to find which means were significantly different from each other. Independent sample $t$ test was performed for the intragroup comparison in terms of age, gender, height, weight and BMI. SPSS version 22.0 was used for analysis and statistical significance was set at $\mathrm{p}<0.05$.

Table 1. Lenke curve type classification

\begin{tabular}{|c|c|c|c|c|}
\hline Type & PT & MT & TL/L & Description \\
\hline 1 & (NS) & $\begin{array}{l}\text { Structural } \\
\text { (M) }\end{array}$ & (NS) & $\begin{array}{l}\text { Main thoracic } \\
\text { (MT) }\end{array}$ \\
\hline 2 & Structural & $\begin{array}{l}\text { Structural } \\
\text { (M) }\end{array}$ & (NS) & $\begin{array}{c}\text { Double } \\
\text { thoracic (DT) }\end{array}$ \\
\hline 3 & (NS) & $\begin{array}{l}\text { Structural } \\
\text { (M) }\end{array}$ & Structural & $\begin{array}{l}\text { Double major } \\
\text { (DM) }\end{array}$ \\
\hline 4 & Structural & $\begin{array}{l}\text { Structural } \\
\text { (M) }\end{array}$ & Structural & $\begin{array}{l}\text { Triple major } \\
\text { (TM) }\end{array}$ \\
\hline 5 & (NS) & (NS) & $\begin{array}{l}\text { Structural } \\
\text { (M) }\end{array}$ & $\begin{array}{c}\text { Thoraco } \\
\text { lumbar/ } \\
\text { Lumbar } \\
\text { (TL/L) }\end{array}$ \\
\hline 6 & (NS) & Structural & $\begin{array}{l}\text { Structural } \\
\text { (M) }\end{array}$ & $\begin{array}{c}\text { Thoraco } \\
\text { lumbar/ } \\
\text { Lumbar - } \\
\text { Main thoracic } \\
\text { (TL/L-MT) }\end{array}$ \\
\hline
\end{tabular}

PT - Proximal Thoracic, M - Major, NS - Either there is no lateral curve or if there is a curve that is not structural.

\section{RESUlTS}

There were 75 AIS patients of which 69 (92\%) were girls. Their ages ranged from 10 to 18 years with a mean age 14.73 \pm 1.73 . There was no significant difference in age, height, weight and BMI between the patients' group and the control group $(\mathrm{p}>0.05)$.

Mean Cobb value in patients was $34.64 \pm 14.05$ with 46 $(61.33 \%)$ having their major curves with the convexity to the right side. As shown in Table 2, Lenke curve types varied by 


\section{International Journal of Engineering Applied Sciences and Technology, 2020 \\ Vol. 5, Issue 5, ISSN No. 2455-2143, Pages 8-13 \\ Published Online September 2020 in IJEAST (http://www.ijeast.com)}

frequency. The mean Cobb value varied in the different Lenke curve types. The commonest type was type 1 (MT) (Figure 1) $(n=33,44 \%)$, the least common was type 6 (TL/L-MT) $(n=7$, 9.3\%). There were no patients with Lenke type 4 (three structural curves). Majority had single structural curves $(65.3 \%)$ (Lenke types 1 and 5). Out of the patients with double structural curves, majority $(72.9 \%)$ had their major curve in the thoracic area.

Table 2. Distribution of curve types and Cobb angle values among AIS patients

\begin{tabular}{lllll}
\hline \multicolumn{1}{c}{ Curve Type } & $\mathrm{N}$ & $\%$ & Age & Cobb \\
& & & (years) & Angle $\left({ }^{0}\right)$ \\
\hline Main Thoracic (MT) & 33 & 44 & 14.8 & 33 \\
Double Thoracic (DT) & 9 & 12 & 15.3 & 34 \\
Double Major (DM) & 10 & 13.3 & 14.8 & 42 \\
$\begin{array}{l}\text { Thoraco } \\
\text { Lumbar/Lumbar (TL/L) }\end{array}$ & 16 & 21.3 & 14.5 & 38 \\
$\begin{array}{l}\text { Thoraco } \\
\text { Lumbar/Lumbar - Main } \\
\text { Thoracic (TL/L - MT) }\end{array}$ & 7 & 9.3 & 14.3 & 25 \\
\hline \multicolumn{1}{c}{ Total } & 75 & 100.0 & 14.7 & 34 \\
\hline
\end{tabular}

Mean values of ROM of hip joint movements of both patient group and normal group are shown in Table 3. Frontal and sagittal plane hip ROMs were significantly reduced in AIS compared to normal group $(\mathrm{p}<0.05)$. External rotation had a higher mean value in patients' group than normal group, but that difference was not significant.

The mean values of ROM of hip movements in different Lenke types are listed in Table 4 and illustrated in Figure 3. One-way ANOVA test showed a significant difference only in the flexion ROM among the curve types at the alpha $=0.05$ significance level, $F(4,70)=3.72, p=0.008$. Further analysis with the post hoc Tukey HSD test, showed that flexion ROM was significantly reduced in the curve type 3 (Figure 2) compared to other curve types.
Fig. 1. Lenke type 1

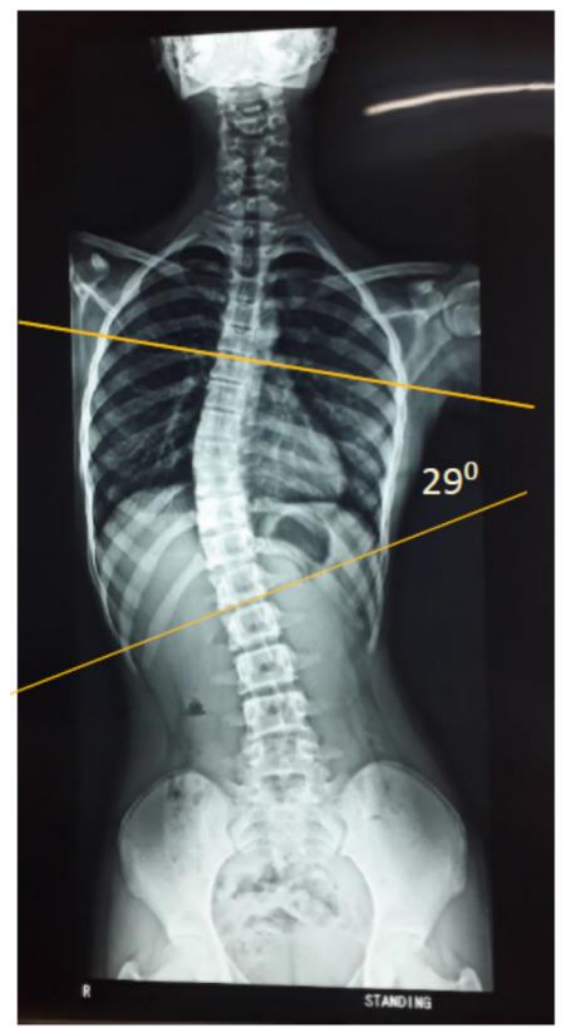

Fig. 2. Lenke type 3

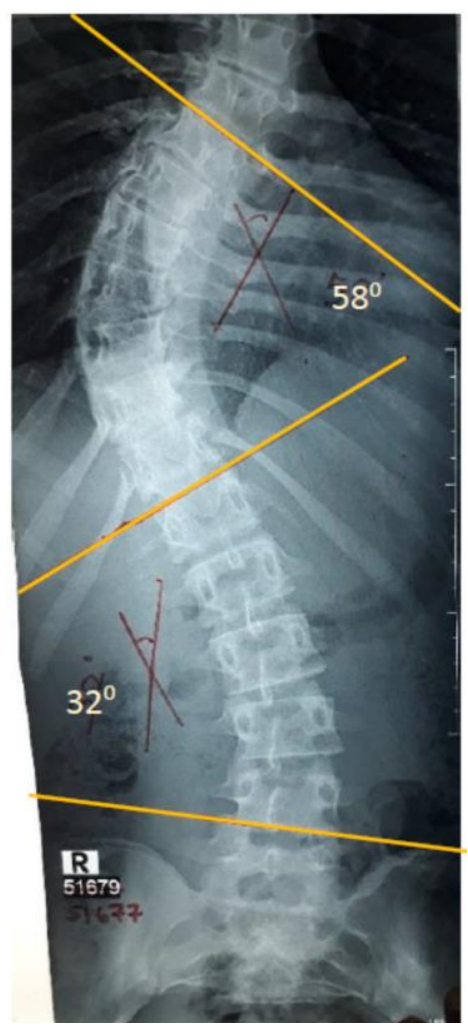


Published Online September 2020 in IJEAST (http://www.ijeast.com)

Table 3. Mean Hip joint ROM values of patients and normal group

\begin{tabular}{llllcc}
\hline $\begin{array}{l}\text { Movement } \\
\text { (Right+Left)/2 }\end{array}$ & Patients & Normal & t & df & Sig. (2-tailed) \\
\hline Flexion & Mean (SD) & Mean $($ SD) & & p value \\
Extension & $98.97(9.09)$ & $116.72(9.33)$ & -8.86 & 52.21 & $\mathbf{0 . 0 0 0}$ \\
Abduction & $20.45(4.06)$ & $25.53(5.93)$ & -4.31 & 40.35 & $\mathbf{0 . 0 0 0}$ \\
Adduction & $30.69(5.41)$ & $36.38(4.12)$ & -5.82 & 69.79 & $\mathbf{0 . 0 0 0}$ \\
External rotation & $33.08(6.35)$ & $29.88(2.59)$ & -6.54 & 76.74 & $\mathbf{0 . 0 0 0}$ \\
Internal rotation & $37.03(4.62)$ & $32.56(5.98)$ & 0.39 & 56.58 & 0.694 \\
\hline
\end{tabular}

Table 4. Hip ROM values of different Lenke curve types

\begin{tabular}{|c|c|c|c|c|c|c|c|}
\hline \multirow{2}{*}{$\begin{array}{l}\text { Sum of the } \\
\text { movement } \\
\text { (right + left) } / 2 \text { Mean } \\
\text { (SD) }\end{array}$} & \multicolumn{5}{|c|}{ Curve type } & \multirow[t]{2}{*}{$\mathrm{F}$} & \multirow{2}{*}{$\begin{array}{l}\text { Sig. }(2 \text {-tailed) } \\
\mathrm{p}-\text { value }\end{array}$} \\
\hline & $\begin{array}{l}1 \\
\mathrm{MT} \\
\mathrm{n}=33\end{array}$ & $\begin{array}{l}2 \\
\text { DT } \\
n=9\end{array}$ & $\begin{array}{l}3 \\
\mathrm{DM} \\
\mathrm{n}=10\end{array}$ & $\begin{array}{l}5 \\
\mathrm{TM} \\
\mathrm{n}=16\end{array}$ & $\begin{array}{l}6 \\
\text { TL/L-MT } \\
n=7\end{array}$ & & \\
\hline Flexion & $99.30(8.50)$ & $102.28(6.13)$ & $90.45 \#(8.85)$ & $99.24(8.94)$ & $104.86(6.33)$ & 3.72 & 0.008 \\
\hline Extension & $19.41(3.22)$ & $19.44(4.73)$ & $23.20(3.13)$ & $20.97(4.73)$ & $21.50(5.09)$ & 2.13 & 0.087 \\
\hline Abduction & $30.23(5.87)$ & 30.83 (4.07) & $33.50(5.21)$ & $29.59(5.91)$ & $31.21(3.04)$ & 0.91 & 0.462 \\
\hline Adduction & $25.11(3.70)$ & $26.55(4.54)$ & $27.20(3.80)$ & $25.13(2.93)$ & $26.43(4.61)$ & 0.88 & 0.482 \\
\hline $\begin{array}{l}\text { External rotation } \\
\text { total }\end{array}$ & $32.85(6.46)$ & $34.55(5.96)$ & 30.50 (6.59) & $33.31(6.83)$ & $35.50(4.92)$ & 0.76 & 0.533 \\
\hline Internal rotation total & $36.24(4.84)$ & $36.83(4.78)$ & $38.40(3.93)$ & 37.09 (4.79) & $38.92(4.05)$ & 0.75 & 0.563 \\
\hline
\end{tabular}

\# Significantly different from values of other curve types 


\section{International Journal of Engineering Applied Sciences and Technology, 2020 \\ Vol. 5, Issue 5, ISSN No. 2455-2143, Pages 8-13 \\ Published Online September 2020 in IJEAST (http://www.ijeast.com)}

\section{DISCUSSION}

The commonest Lenke type in our study was type 1 similar to previous studies $[5,6,8,13,14]$. Lenke type 4 was not found in the present study. Although the results were fairly similar between our study and previous studies, the order of prevalence was different. Type 5 was the second most prevalent curve type in our study and Farshad's study [13], while type 2 was the second most common type in two other studies $[5,6]$.

Main difference between the above studies and the present study is the treatment method followed by the participants and therefore the Cobb angle range. Previous studies have included only the patients who were surgically operated $[5,6,14]$ or had an indication for surgery [8] whereas our study included only conservatively managed AIS patients. In usual practice AIS patients are operated only if their curves are higher than 40 or 50 degrees, and the patients with lesser Cobb angle values are managed conservatively [15-18]. Hence, in the present study, there was a deviation of the Cobb angle range towards lower values and had a comparatively low mean Cobb angle value.

In a study conducted by Lee et al in 2005 [15] including AIS patients with curves higher than 100 , found that $67.1 \%$ of the patients had thoracic curves and thoracolumbar and lumbar in $23 \%$ and $9.9 \%$ respectively. This study does not provide details regarding classification criteria. If only the location of the major curve is considered the results of this study is similar to the results of the present study which had $69.3 \%$ thoracic involvement.

Mahaudens et al (2009) [11] found a significant reduction in step length and frontal plane hip movements in AIS patients when compared to normal individuals. These findings are supported by our results, which shows a significant reduction in ROM of frontal and sagittal plane hip movements in AIS than normal subjects. Hip flexion ROM contributes to step length. As we found, Lenke type 3 curves had a significant reduction in hip flexion ROM, they may be more affected by reduction of step length. However, we couldn't find any evidences from previous literature to support this finding. Hence it is yet to be investigated what is the underlying biomechanical mechanism and/or the anatomical relationship of this association.
Kotwicki et al (2008) [19] found numerous asymmetries around the hip joint of AIS patients. Also, it is well documented in the literature that the pelvic disorders are secondary to lumbar scoliosis $[9,10]$. Hence we hypothesize that the curve types which has major curves in lumbar area (type 5 and type 6) would have significantly less mean values in hip ROM than curve types which doesn't have major curves in lumbar area or which has major curves in thoracic area (types 1, 2 and 3 ) due to the close anatomical and biomechanical relationship of the lumbar spine with the pelvis and hence the hip joint [20]. Though the flexion movement differ significantly among curve types, it failed to support this hypothesis. Gum and his co-workers (2007) [8] found a relationship between thoracic curves and pelvic structure. According to that, there is an abnormal transverse pelvic rotation in AIS patients in the same direction as the thoracic curve. This relationship was found only in Lenke curve types 1,2 and 3 .

After further reviewing the results of above-mentioned studies [8-10], it is evident that the pelvis gets affected in all the curve types. This includes types 5 and 6 according to Walker and Dickson (1984) [21], Cole et al (1990) [9] and Mahaudens et al (2005) [10] and types 1, 2 and 3 according to Gum et al (2007) [8]. In our study we found significant impairments of hip ROM in frontal and sagittal plane hip movements in all the curve types. Hence it can be suggested that this impairment in hip ROM in AIS patients is due to the pelvic disorders which occurs as a secondary complication of the scoliotic curve.

Comparatively smaller sample size and non-assignment of lumbar modifier and sagittal modifier when classifying the curve types are possible limitations of this study.

\section{CONCLUSION}

It can be concluded that the most prevalent curve type among AIS in Sri Lanka is Lenke type 1, irrespective of the Cobb angle range and the treatment method. Thoracic area (Lenke types 1,2, and 3) is more affected than the lumbar area (Lenke types 5 and 6), also the majority of the patients have single curves (Lenke types 1 and 5) than double or triple curves (Lenke types 2, 3, 4, and 6). Although the frontal and sagittal plane hip ROMs were significantly reduced in AIS compared to normal, only flexion ROM showed a statistically significant association with different curve types. Flexion ROM in Lenke type 3 was significantly less compared to other curve types. The reduction in flexion ROM would have contributed for the reduction in step length of AIS than normal as found in previous literature. According to these results it is wise to consider hip flexion ROM exercises in conservative management of AIS patients, specially the patients with Lenke type 3 curves. 


\section{International Journal of Engineering Applied Sciences and Technology, 2020 \\ Vol. 5, Issue 5, ISSN No. 2455-2143, Pages 8-13 \\ Published Online September 2020 in IJEAST (http://www.ijeast.com)}

\section{REFERENCE}

1. Adolescent Idiopathic Scoliosis | Scoliosis Research Society [Internet]. [cited 2017 Jan 5];Available from: https://www.srs.org/professionals/online-educationand-resources/conditions-and-treatments/adolescentidiopathic-scoliosis

2. Instructional Course Lectures TAA of OS. Cobb, J., Outline for the study of scoliosis. Instr. Course Lect. Am. Acad. Orthop. Surg. 2012;5:(AAOS): Ann Arbor; 261-275. 1948.

3. Cheung W., Luk DD. Focus On Classification of adolescent idiopathic scoliosis. Br. Editor. Soc. Bone Jt. Surg. [Internet] 2013;1-4. Available from: http://www.boneandjoint.org.uk/content/focus/classifi cation-adolescent-idiopathic-scoliosis

4. Lenke LG, Edwards CC, Bridwell KH. The Lenke classification of adolescent idiopathic scoliosis: How it organizes curve patterns as a template to perform selective fusions of the spine. Spine (Phila. Pa. 1976). 2003;28:s199-207.

5. Lenke LG, Betz RR, Clements D, Merola A, Haher T, Lowe $\mathrm{T}$, et al. Curve prevalence of a new classification of operative adolescent idiopathic scoliosis: Does classification correlate with treatment? Spine (Phila. Pa. 1976). 2002;27:604-11.

6. Sponseller PD, Flynn JM, Newton PO, Marks MC, Bastrom TP, Petcharaporn M, et al. The association of patient characteristics and spinal curve parameters with lenke classification types. Spine (Phila. Pa. 1976). 2012;37:1138-41.

7. Fujimori T, Bastrom TP, Bartley CE, Newton PO. Comparison of typical thoracic curves and atypical thoracic curves within the Lenke 1 classification. Spine Deform. [Internet] 2014;2:308-15. Available from: http://dx.doi.org/10.1016/j.jspd.2014.03.009

8. Gum JL, Asher MA, Burton DC, Lai SM, Lambart LM. Transverse plane pelvic rotation in adolescent idiopathic scoliosis: Primary or compensatory? Eur. Spine J. 2007;16:1579-86.

9. Cole A, Burwell RG, Jacobs AJ. Hip rotation, knee rotation and emoral anteversion in healthy subjects and in children with adolescent idiopathic scoliosis; relation o hip rotation to lateral spinal curves . 1990;

10. Mahaudens P, Thonnard JL, Detrembleur C. Influence of structural pelvic disorders during standing and walking in adolescents with idiopathic scoliosis. Spine J. 2005;5:427-33.

11. Mahaudens P, Banse X, Mousny M, Detrembleur C.
Gait in adolescent idiopathic scoliosis: Kinematics and electromyographic analysis. Eur. Spine J. 2009;18:512-21.

12. Gajdosik RL, Bohannon RW. Clinical Measurement of Range of Motion. Phys. Ther. 1987;67:1867-72.

13. Farshad M, Catanzaro S, Schmid SL. The Spinopelvic Geometry in Different Lenke Curve Types of Adolescent Idiopathic Scoliosis. Spine Deform. [Internet] 2016;4:425-31. Available from: http://dx.doi.org/10.1016/j.jspd.2016.08.003

14. Hoashi JS, Cahill PJ, Bennett JT, Samdani AF. Adolescent Scoliosis Classification and Treatment. Neurosurg. Clin. N. Am. [Internet] 2013;24:173-83. Available from: http://dx.doi.org/10.1016/j.nec.2012.12.006

15. Lee WTK, Cheung CSK, Tse YK, Guo X, Qin L, Lam $\mathrm{TP}$, et al. Association of osteopenia with curve severity in adolescent idiopathic scoliosis: A study of 919 girls. Osteoporos. Int. 2005;16:1924-32.

16. Kotwicki T, Walczak A, Szulc A. Measurement of the hip joint range of motion in adolescent girls with idiopathic scoliosis. Scoliosis 2009;4:1.

17. Poussa M, Mellin G. Spinal Mobility and Posture in Adolescent Idiopathic Scoliosis at Three Stages of Curve Magnitude. Spine (Phila. Pa. 1976). 1991;17:757-60.

18. Oakley PA. Is early treatment for mild adolescent idiopathic scoliosis superior over the traditional "watch \& wait" approach? A case report with longterm follow-up.

19. Kotwicki T, Walczak A, Szulc A. Trunk rotation and hip joint range of rotation in adolescent girls with idiopathic scoliosis: Does the "dinner plate" turn asymmetrically? Scoliosis 2008;3:1-11.

20. Tully EA, Wagh P, Galea MP. Lumbofemoral rhythm during hip flexion in young adults and children. Spine (Phila. Pa. 1976). 2002;27.

21. Walker A, Dickson RA. School screening and pelvic tilt scoliosis. Lancet 1975;305:390. 